\title{
Correction to: Statistical Inference for Type-I Generalized Birnbaum-Saunders Distribution
}

\author{
Ronghua Wang ${ }^{1} \cdot$ Naijun Sha $^{2}$ - Xiaoling $\mathrm{Xu}^{3}$
}

(C) The Indian Society for Probability and Statistics (ISPS) 2018

\section{Correction to: J Indian Soc Probab Stat https://doi.org/10.1007/s41096-018-0044-1}

The funding information was missing in the original version of this article. The correct funding information is given below:

Funding Wang's work was supported by National Natural Science Foundation of China (11671264). Sha's work was partially supported by NSF CMMI-0654417 and NIH NIMHD-2G12MD007592.

The online version of the original article can be found under https://doi.org/10.1007/s41096-018-0044-1.

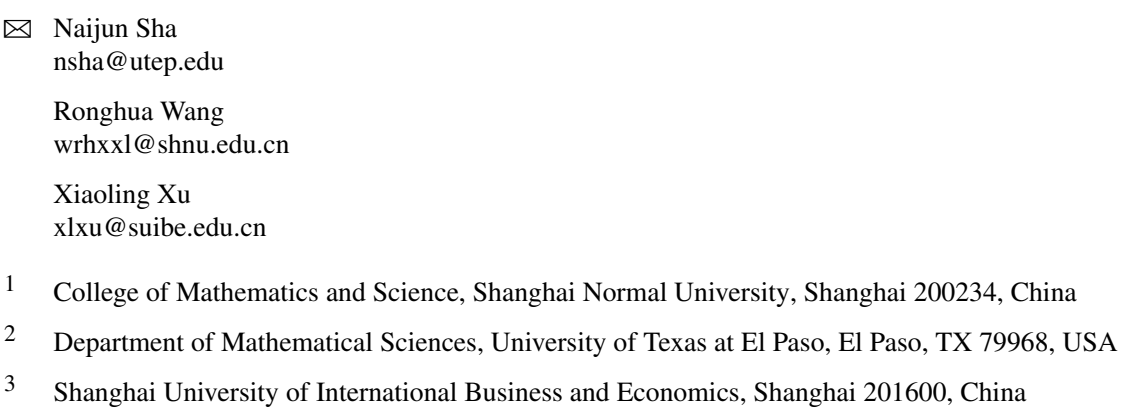

